\title{
LIDERANÇA DO EDUCADOR E EMPODERAMENTO DO EDUCANDO COMO INSTRUMENTALIZAÇÃ̂O NO CONSTRUTO ÉTICO-MORAL-SOCIAL SOB A ÓTICA FREIRIANA
}

\author{
EDUCATOR LEADERSHIP AND EDUCATING EMPOWERMENT AS \\ INSTRUMENTALIZATION IN THE ETHICAL-MORAL-SOCIAL CONSTRUCT UNDER THE FREIRIAN \\ PERSPECTIVE
}

\begin{abstract}
1.Mestre Profissional em Gestão nas Organizações Aprendentes (PPGOA/UFPB)

E-mail: eduardo.arruda73@gmail.com

2.Mestrando Profissional em Gestão nas Organizações Aprendentes (PPGOA/UFPB)

E-mail: hugomsouto@gmail.com

3. Doutor em Educação (PPGE/UFRN), Professor do PPGOA/UFPB

E-mail: wilsonaragao@hotmail.com
\end{abstract}

\section{ACESSO ABERTO}

Copyright: Esta obra está licenciada com uma Licença Creative Commons Atribuição 4.0 Internacional. $(\mathrm{cc})$ EY

Conflito de interesses: A autora declara que não há conflito de interesses.

Financiamento: Não há.

Declaração de Disponibilidade dos dados: Todos os dados relevantes estão disponíveis neste artigo.

Recebido em: 20/09/2019.

Revisado em: 01/10/2019.

Aceito em: 10/10/2019.

\section{Como citar este artigo:}

ARRUDA, Eduardo Martins de; SOUTO, Hugo Medeiros; ARAGÃO, Wilson Honorato. Liderança do educador e empoderamento do educando como instrumentalização no constructo éticomoral-social sob a ótica freiriana. Informação
Eduardo Martins de Arruda ${ }^{1}$ (iD) Hugo Medeiros Souto ${ }^{2}$ Wilson Honorato Aragão ${ }^{3}$ em Pauta, Fortaleza, v. 4, n. especial, p. 176-191, nov. 2019. DOI:

https://doi.org/10.32810/25253468.ip.v4iEspecial.2019.42613.176-191.

\section{RESUMO}

Liderança e empoderamento são temas amplamente discutidos em contextos organizacionais. Porém, quando se parte para aplicação desses conceitos no contexto pedagógico, mais precisamente nas relações educador-educando, relevam-se campos ainda incipientes, carentes de estudos e pesquisas científicas. Pensando na importância dos temas na pedagogia e apoiado na vida e obra de Paulo Freire, este estudo tem como objetivo compreender as relações interpessoais presentes em meios educacionais e como podem ser aperfeiçoadas e inspiradas por princípios presentes em seu legado, como amor ao próximo, justiça, liberdade, humildade, pensamento crítico e ética. Para tanto, utilizouse como método a revisão teórica de conceitos como liderança, empoderamento, educação e pedagogia com base no estudo da obra freiriana. Pudemos compreender que a escola não mais se configura como único ou sequer como o local principal onde ocorrem as manifestações de ensino-aprendizagem. Consequentemente, o papel de educador não mais se concentra no professor de sala de aula. Da análise mais apurada das relações de liderança e empoderamento entre educador e educando, se obteve como resultado que a responsabilidade na construção de uma sociedade mais humanista e igualitária compete a cada indivíduo que se encontra no papel de educador, viabilizando aos educandos o desenvolvimento de uma leitura de 
mundo crítica e instrumentalizada, baseada em princípios freirianos e da consciência da própria realidade, tornando-o capaz de transformá-la.

Palavras-chave: Educação. Liderança. Empoderamento. Práxis freiriana.

\section{ABSTRACT}

Leadership and empowerment are themes widely discussed in organizational contexts. However, when it comes to the application of these concepts in the pedagogical context, more precisely in educator-educating relations, they are revealed as still incipient fields, lacking in studies and scientific research. Thinking about the importance of these themes in pedagogy and supported by the life and work of Paulo Freire, this study aims to understand the interpersonal relationships present in educational environments and how they can be improved and inspired by principles present in his legacy, such as love, justice, freedom, humility, critical thinking and ethics. For that, the theoretical revision of concepts such as leadership, empowerment, education and pedagogy based on the study of the Freirian work was used as method. We can understand that the school no longer configures itself as the sole or even the main place where the manifestations of teaching-learning take place. Consequently, the role of educator no longer focuses on the classroom teacher. Learning can take many forms, often as an unconscious process, in which the responsibility of educating lies in all who transmit knowledge and interact with those who receive it. From the closer analysis of leadership and empowerment relations between educator and educator, the result was that responsibility for the construction of a more humanistic and egalitarian society rests with each individual who is in the role of educator, enabling the students to develop a critical and instrumental world reading, based on Freirian principles and the awareness of reality itself, making it capable of transforming it.

Keywords: Education. Leadership. Empowerment. Freirean praxis.

\section{INTRODUÇÃO}

Com as mudanças culturais ocorridas na sociedade nos últimos 50 anos, impulsionadas muitas vezes pelos avanços das tecnologias da informação, novos padrões de comportamentos surgem e novas formas de enxergar e vivenciar o mundo são construídas em várias dimensões da vida humana. Espera-se que avanços tecnológicos atuem em prol da difusão de conhecimentos, no esclarecimento das pessoas, e as ajudem principalmente a entender seu papel no mundo, de ser humano, um ser naturalmente social.

Entretanto, a tecnologia é apenas um dos fatores que podem viabilizar a construção de uma vida melhor, mais humana, mais prática, através da sua facilidade em aproximar pessoas, derrubando barreiras de tempo e espaço. Wilson (2011) demonstra, através de índices e de casos sucedidos em alguns países, que "a educação é fundamental e central para se criar um mundo melhor para todos, no qual as pessoas podem ter uma vida longa e saudável, acesso à educação e um nível de vida apropriado". Se mostra então como o ingrediente principal uma sociedade mais cidadã e humanitária a boa formação do indivíduo, que atravessa os limites da escola e se torna um compromisso de todos. 
A educação ainda não é vista como prioridade para muitos governos, pois carrega em si a semente da libertação. Segundo Paulo Freire, a educação carrega em si o potencial de libertar o oprimido do seu opressor. Nesse sentido,

Freire avança por meio de uma visão antropológica inovadora, ao valorizar a subjetividade, o papel da conscientização, a problematização de consciência crítica nas relações de poder e interesses de classe, a interação do sujeito na realidade social e o sentido da educação e da transformação cultural (ZITKOSKI, 2010, p. 19).

Desenvolvendo essa ideia, fica evidente que a educação dentro da práxis freiriana representa o empoderamento das classes menos favorecidas, de grupos minoritários e de tantas outras vozes amordaçadas que, à medida que tomam consciência de sua própria realidade e das verdadeiras causas dos problemas que os assolam, tornam-se capazes de não mais aceitá-las como imutáveis ou como algo natural. Tornando-se sujeitos da sua própria história, instrumentalizados de conhecimento e sabedoria, são capazes de libertar tantos outros indivíduos, como a si próprio, concretizando uma sociedade mais ética e moral, justa e igualitária, baseada em princípios universais e, antes de tudo, humanos. Compartilhando com esse pensamento, Zitkoski afirma:

O conceito de educação em Freire implica entender o ser humano não apenas como razão, estrutura lógica e consciência. Sua concepção antropológica converge para uma visão dinâmica da existência humana, ao valorizar, de forma equilibrada, todas as dimensões de nossa vida: corpo, mente, coração, sentimento, emoções, sentido, intelecto, razão, consciência, entre outros (ZITKOSKI, 2010, p. 22).

Configura-se como objetivo principal deste trabalho entender e compreender como são tecidas as interações pedagógicas entre aqueles que ensinam e os que aprendem, sob uma ótica freiriana, sendo ela pressuposto para questionamentos, tais quais: como construir uma sociedade baseada em princípios éticos, morais e sociais? Como o educando pode se tornar um agente da mudança? Como o educador e o educando podem colaborar na construção do saber?

Com este intuito, o tema liderança se faz presente neste trabalho sob um novo olhar, um ponto de vista diferente do costumeiramente utilizado no meio organizacional ou na Administração. Temos aqui a liderança como uma forma de assunção da própria responsabilidade, perante o mundo enquanto ser humano, principalmente do que o representa no papel de educador perante os educandos, perante o mundo e a si mesmo. É, de fato, a retomada de um velho conceito imbuído sob uma ótica social. 
Jacobs (1970, p. 232) diz que "a liderança é tida como uma interação entre pessoas em que uma apresenta informações de um tipo e de tal forma que o outro se convence de que seus resultados [...] serão melhorados se ele se comporta da maneira sugerida ou desejada. Chiavenato (2000, p. 315) enfatiza que "a liderança é a capacidade de influenciar as pessoas a fazerem aquilo que devem fazer". Desse modo, fica evidente que liderar no contexto pedagógico não pode ser sinônimo de autoritarismo, imposição de hierarquia pelo educador aos educandos ou algo que remeta ao ensino militar. Pelo contrário, liderança nesse contexto é libertar a mente do educando, instrumentalizando o modo pensar. Portanto, implica disseminar valores e princípios nas mentes daqueles que anseiam por conhecimento e ser a luz que guia o desenvolvimento do conhecimento e da razão.

Para concretização deste estudo, foi feita uma análise documental de momentos da vida e obra do mestre e patrono da educação brasileira, Paulo Freire, tais como livros, entrevistas, discursos e conversas informais concedidas à mídia. Metodologicamente, este trabalho está configurado como uma pesquisa exploratória amparada por revisão bibliográfica de algumas das principais obras de Paulo Freire, de obras de outros autores que o referenciam, além de outras obras de temas diversos que interagem com o objeto deste estudo.

A propósito de uma melhor compreensão do conteúdo, o artigo tem seu desenvolvimento divido em três partes: liderança sob o viés freireano; empoderamento do educando: um olhar freiriano; e (c) utopia x realidade: um olhar sobre a práxis freiriana.

\section{LIDERANÇA SOB O VIÉS FREIRIANO}

Para melhor compreensão das relações dialéticas freirianas no contexto pedagógico, será introduzida uma explanação sobre liderança e seus principais pressupostos, buscando principalmente desmitificar a liderança como dominação. Sob a ótica da práxis freiriana, liderar é ser consciente da sua responsabilidade perante o mundo, é agir coerentemente na construção de um mundo melhor, influenciando positivamente as pessoas sem, no entanto, deixar de aprender com os que aparentemente nada têm a ensinar. Nesse sentido, a liderança pedagógica é para Freire uma via de mão dupla, não apenas um monólogo do conhecimento, pois, enquanto o 
professor ensina, também aprende, assim como os educandos ensinam enquanto aprendem.

O educador é um líder a partir do momento que tem consciência do seu papel em conduzir o processo de ensino-aprendizagem, em ser um facilitador perante os educandos na construção da tecitura da rede do conhecimento. Nesse sentido, a seguir serão mais bem trabalhadas as características da liderança em termos acadêmicos sem, contudo, deixar de fazer ponderações ao legado de Freire.

\subsection{Conceitos e tipos de liderança}

Em qualquer livro, site ou obra especializada que se abre sobre o assunto, tem-se que o ato de liderar está relacionado à capacidade de influenciar e conduzir pessoas, grupos ou equipes no alcance de determinados objetivos. Apesar de liderança estar muitas vezes ligada ao conceito de poder ou dominação, neste artigo, a liderança estará mais ligada à capacidade de sugerir e intuir pessoas na mudança em prol de construto ético-social-moral do indivíduo. Tradicionalmente, encontramos na literatura uma divisão de liderança em três tipos: autocrática, democrática e liberal.

A primeira remete ao autoritarismo, representando muitas vezes a liderança com base na posição ocupada e no poder de coerção. Pode ser bem-vinda em situações ou organizações que exigem respostas imediatas, controle pleno ou que envolvem pouca reflexão. No entanto, se surge por defeito de liderança, por pessoas desprovidas de trato com outras pessoas, gerará atritos que tendem a sugar muita energia por parte do líder e desgaste físico e psicológico dos liderados. Nessa condição, sua manutenção pode se tornar insustentável e não produzir resultados esperados. Em estudo sobre o bem-estar pessoal nas organizações, Dessen (2010) pôde correlacionar maiores níveis de satisfação com uma menor percepção da autocracia em seus superiores.

Democrática é a liderança baseada na capacidade dialógica intrínseca no ser humano enquanto ser social. Ela está pautada na comunicação e seu objetivo maior é dar voz a todos que participam do processo, motivando-os e desenvolvendo suas capacidades internas. Nesse tipo de liderança, toda e qualquer opinião é respeitada e levada ao debate para que tenham as mesmas oportunidades de análise. Preconceitos e restrições devem ser desestimulados no grupo em que esse tipo de liderança é trabalhado. 
A última, liberal, também chamada de laissez-faire, é a liderança marcada pela menor intervenção do líder perante seus liderados. Ou seja, as decisões são tomadas majoritariamente pelos liderados sem ou com pouca participação ou influência do líder, que atua mais como um facilitador. Depende de certa maturidade e concisão da equipe e se mostra mais pertinente em equipes de alto domínio técnico para desenvolver tarefas complexas.

Fazendo uma inferência sobre o legado de Freire, é notável implícito e explicitamente o posicionamento pela adoção da liderança democrática no contexto pedagógico. Ou seja, nas relações entre educando e educador, este, consciente do seu papel e de suas responsabilidades perante o mundo, deve motivar e cultivar o espírito participativo e colaborador entre os educandos. Indo mais além, o educador deve fomentar e ajudar a desenvolver habilidades no educando para que, juntos, construam uma teia do conhecimento que não seria possível caso fosse construída somente pelo educador. Não seria tão rica, complexa e aplicável. Desse modo, sob a ótica freiriana, a liderança no contexto pedagógico acontece por meio de decisões e ações conjuntas e em tempo real entre ambas as partes.

Por outro lado, a práxis freiriana se opõe ao conceito de liderança autocrática ou autoritária, não só no contexto pedagógico, mas na vida como um todo, evidente no momento em que tece uma crítica ao que ele convencionou como "educação bancária".

Ou seja, o professor, em seu papel soberano e inquestionável, deveria transmitir conhecimentos para os alunos. Estes, enquanto receptores, deveriam apenas receber esses "depósitos" de informações, tal como uma conta bancária recebe depósitos de dinheiro. Nesse modelo de educação tradicional e ainda muito arraigado na academia, aos alunos não cabe analisar ou questionar a validade dessas informações junto ao professor.

Paulo Freire preferia não utilizar os termos professor e aluno, justamente pela etimologia desses dois termos que corrobora com esse sentido de liderança autoritária, pautada no poder e dominação de um lado e na anulação e passividade do outro. Acreditava numa relação de conhecimento como uma via de mão dupla.

Por fim, na liderança liberal, há um relaxamento demasiado por parte do líder perante os seus liderados, algo que, de maneira geral, não condiz com o encontrado na obra de Freire, que reforça a responsabilidade dos indivíduos perante o mundo e os demais indivíduos que estão a sua volta. Desse modo, o educador não pode fugir da sua 
responsabilidade, enquanto formador pedagógico comprometido com o desenvolvimento e formação de seres humanos, a ponto de figurar como um mero participante-convidado.

Para Freire, a liderança no processo ensino-aprendizagem também deve ser democrática no sentido de o educando ter relativa liberdade de escolher quais assuntos deverão ser estudados, respeitando os eixos básicos para cada nível de ensino, além de poder sugerir como os temas podem ser mais bem trabalhados em sala de aula.

\subsection{Aspectos da liderança no contexto pedagógico}

Em meio aos desafios enfrentados, o educador, enquanto líder pedagógico, precisa se reinventar a todo instante, buscar suas motivações e preferências e trazer todos esses seus sentimentos de engajamento e "descoberta de mundos" para os educandos. É preciso fazer com que os educandos se sintam parte do processo e não sejam apenas meros expectadores. Nesse aspecto, muitos educadores e, mais especificamente, professores perguntam se possuem as competências necessárias para a sala de aula atual.

Na educação, o conceito de competência se afirma mais com o aprimoramento de múltiplas capacidades. De certo modo, esse pensamento remete ao conceito de inteligências múltiplas proposto por Gardner (1996), em que todo ser humano possui várias inteligências em diversas áreas, porém algumas se sobressaem em relação a outras, por diversos fatores, enquanto outras ainda permanecem adormecidas ou nunca se manifestaram de maneira significativa para determinado indivíduo.

Chiavenato (2000) explana que competência está baseada na soma e interação de três fatores cruciais: (a) conhecimento: ter a informação, buscar sempre aprender, aprimorar-se sempre; (b) habilidade: aplicar com o conhecimento adquirido, enxergar novas possibilidades para as informações adquiridas; (c) atitude: ser proativo, tornar em ato prático o conhecimento processado e as habilidades desenvolvidas.

Freire acredita numa liderança pedagógica baseada no amor e no poder transformador da educação na vida das pessoas, libertando-as das amarras e mordaças sociais que as impedem de enxergar ou as faz enxergar parcialmente a opressão sistemática que as assolam. Assim, tornam-se solitárias e incapazes de vencer as forças dominantes. 
Entre as várias maneiras de contextualizar liderança, a abordagem que mais se aproxima da práxis freiriana é a liderança por princípios de Stephen Covey. Nesse sentido, a liderança, para Covey (1998), só é perene e salutar quando está atrelada a princípios humanos e éticos, como justiça, igualdade social, solidariedade, integridade, honestidade, confiança, entre outros. Também aponta que a insatisfação pode ser o elemento-chave para mudanças na vida pessoal e para gerar comportamentos pessoais baseados em princípios éticos e morais que conduzem a melhores relações humanas.

Neste contexto, os princípios são como máximas universais e podem ser aplicados em qualquer situação, em qualquer tempo ou lugar, tais como a bondade e o agir de boa-fé. Vale ressaltar que não se confundem com valores, que são mais superficiais e ligados à cultura ou a uma época. Ou seja, os valores mudam com o tempo; os princípios, dificilmente.

Fazendo um paralelo da abordagem de liderança de Covey (1998) com o pensamento freiriano, pode-se esperar que o educador deverá exercer sua liderança por meio do desenvolvimento e do estímulo a um sistema de valores que estejam pautados em princípios da vida humana. Porém, isso requer coragem e humildade por parte dos líderes para aprender e crescer continuamente. No contexto pedagógico, o professor deve sempre estar atento, observando, ouvindo, percebendo necessidades e dúvidas dos educandos, ao mesmo tempo em que deve buscar constantemente novos conhecimentos e novas formas de aprender.

Corroborando o pensamento freiriano, Covey (1998) elenca algumas características que tais líderes devem possuir, tais como:

Quadro 1 - Características que os líderes devem possuir

Aprendizado permanente: como já exposto neste trabalho, o aprimoramento, ter em mente que as habilidades estão sempre em expansão, basta encontrar uma razão que o guie.

A vida como uma missão: encontrar na vida um sentido maior e não apenas a mera consequência do acaso;

Irradiar energia positiva.

Ser otimista, alegre e espirituoso frente as adversidades;

Acreditar na humanidade, na capacidade humana de agir para o bem comum;

Possuir uma vida social equilibrada, cultivar as verdadeiras amizades e se relacionar amistosamente com o meio circundante;

Sentir-se feliz com o sucesso das outras pessoas;

Ser catalisadores de mudanças, ser proativos;

Exercitam sua mente por meio da leitura, da solução criativa de problemas, etc.

Fonte: Adaptado de Covey (1998, grifo nosso). 
Líderes em ambiente pedagógico podem ainda seguir dois vieses de atuação no meio: como facilitador e como mentor. No primeiro caso, podemos citar o educador que promove a interação entre a turma, que estimula a colaboração entre os educandos e a dissolução de qualquer conflito ou preconceito que surja. Já o educador sob o viés de mentor vai além, atuando como uma espécie de padrinho educacional do educando. Nesse sentido, o educador sob a faceta de mentor se preocupa e age de modo a compreender as necessidades individuais de seus educandos, apoiando-os e aconselhando-os de forma que cada um que possa escrever sua própria história de maneira mais assertiva e mais alinhada à sua identidade e anseios pessoais.

Outro aspecto relacionado ao tema trata da questão atual do ensino a distância (EaD) e relações entre professor e aluno nesse meio. Felizmente, o EaD já não é nenhuma novidade e o Brasil tem avançado bastante na área de infraestrutura e produção de conteúdos educacionais a distância.

Nesse sentido, quando corretamente implementado, tem como uma das características a democratização do conhecimento. De toda forma, o EaD possui características que podem dialogar com os princípios freirianos, tais como a flexibilidade na relação tempo-espaço nos estudos, uso de abordagens pedagógicas alternativas mediadas por tecnologia, como jogos, fóruns, trabalhos colaborativos e redes sociais, entre outras.

Um conceito levantado por Freire, ao contrário dos que muitos pensam, é que o papel de educador nem sempre está somente na figura formal do professor. Por exemplo, se pensarmos no contexto escolar, são educadores: o porteiro, o diretor, a moça da limpeza e vários outros atores. Todos nós somos educadores quando temos algo a contribuir na construção de um mundo mais cidadão. Diante dessa realidade, a liderança também é situacional ou contingencial. Ou seja, os líderes se comportam de acordo com as circunstâncias do momento e podem se adequar às mais variadas necessidades.

\section{EMPODERAMENTO DO EDUCANDO: UM OLHAR FREIRIANO}

Empoderar, de maneira simplista, é prover alguém ou a si mesmo de poder. É passar de uma situação mais restritiva para outra mais favorecida, no sentido de se sentir mais autônomo ou capaz de influenciar e mudar pessoas e o curso das coisas. 
Equivocadamente, quando se pensa em empoderamento do educando, num primeiro momento, se pensa no estudo como um meio de salvação para pessoas pobres e menos favorecidas. Tem-se que o estudo é uma das maneiras de superar a pobreza material, enquanto fenômeno individual, e ter uma vida melhor financeiramente para si e seus familiares. De algum modo, as pessoas que estudam adequadamente têm mais chances de superar as dificuldades financeiras por estarem mais bem capacitadas para melhores oportunidades. Porém, talvez o erro esteja na simplicidade deste pensamento, sendo o empoderamento por meio da educação algo bem mais complexo e que abrange várias dimensões do ser humano, sendo a melhora nas condições econômicas apenas uma das facetas desse fenômeno. Freire, em sua obra "Pedagogia da Esperança", corrobora com esse pensamento de sentido mais holístico e filosófico sobre empoderamento por meio da educação: "Hoje, mais do que em outras épocas, devemos cultivar uma educação da esperança enquanto empoderamento dos sujeitos históricos desafiados a superarmos as situações limites que nos desumanizam a todos" (1994, p. 11).

Sob um viés político, para Freire, o empoderamento dos educandos representa também a libertação do indivíduo em relação às amarras político-sociais: "A função central da educação de teor reconstrutivo político é a de desfazer a condição de massa de manobra, como bem queria Paulo Freire" (DEMO, 2001, p. 320).

Nesse aspecto, sob uma ótica freiriana, fica evidenciado que empoderar os educandos de bons sentimentos, de noções de respeito e cidadania, construir relações éticas e morais, ensinar a trabalharem as dificuldades, motivar e ajudar os educandos a entenderem o seu papel na comunidade, na sociedade e no mundo é mais que um dever do educador: é comprometimento com uma missão, um ofício de amor ao próximo.

Freire (1969), na sua obra "Educação como prática de liberdade", enxerga um viés essencialmente social na questão do empoderamento. Enfatiza sua convicção de que se trata também de um processo concretizado por meio das interações sociais, através da problematização da realidade, dos esforços comuns para encontrar soluções e para alcançar a consciência, que vai sendo construída coletivamente. Isso possibilita uma união pelo combate à dominação e à opressão político-econômica-social.

Ainda enfatizando o aspecto social e moral do empoderamento na visão freiriana, vale destacar que: 
Mesmo quando você se sente, individualmente, mais livre, se esse sentimento não é um sentimento social, se você não é capaz de usar sua liberdade recente para ajudar os outros a se libertarem através da transformação da sociedade, então você só está exercitando uma atitude individualista no sentido de empowerment ou da liberdade (FREIRE, 1986, p. 135).

Nas relações dialógicas entre educadores e educandos, o empoderamento destes por meio dos educadores acontece no dia a dia através da libertação do pensamento, do exercício crítico da mente e da autonomia, do incentivo à criatividade e à liberdade de expressão. Ou seja, o educador deve planejar suas atividades letivas baseadas no comprometimento que lhe é próprio, de formar seres humanos para a vida e para o enfrentamento dos problemas pertinentes à sua realidade, não meramente para uma profissão ou para conclusão de estudos de base. Contudo, o problema parece ser muito mais político e ideológico do que uma questão de falta de iniciativa individual de cada educador. Poucos professores, mesmo que sejam fiéis aos ideais de educação libertadora, conseguem encontrar um ambiente propício para exercitar uma pedagogia libertadora dentro das escolas, faculdades e universidades, pois há muita resistência de forças políticas.

Um dos principais dilemas encontrados em Freire é o conflito interior existente na saída da condição de oprimido:

Os oprimidos, que introjetam a "sombra" dos opressores e seguem suas partes, temem a liberdade, na medida em que esta, implicando a expulsão desta sombra, exigiria deles que preenchessem o vazio pela expulsão com outro "conteúdo" - o de sua autonomia (Freire, 1993, p. 34).

O empoderamento por parte do educando está intrinsecamente ligado ao tema da dialogicidade como um dos fatores para a conquista da autonomia e do verdadeiro sentimento de empoderamento. Nesse sentido, sabe-se que a dialogicidade é a base para uma vida menos dificultosa e embaraçosa, pois muitos problemas encontrados no dia a dia surgem da falta de uma comunicação adequada. Mesmo onde ela aparentemente existe, carece de diálogo.

Freire atribui ao diálogo um caráter fenomenológico e o configura como um componente construtor da história:

O diálogo fenomeniza e historiza a essencial intersubjetividade humana; ele é relacional e, nela, ninguém tem iniciativa absoluta. Os dialogantes "admiram" um mesmo mundo; afastam-se dele e com ele coincidem; nele põem e opõem-se [...]. 0 diálogo não é produto histórico, é a própria história. (Fiori apud Freire, 1993, p. 16). 
Desse modo, as relações entre educando e educador não podem jamais se restringir a um monólogo em que o professor passa horas replicando conceitos em sala de aula e os alunos se dão por satisfeito a não discordarem ou não contribuírem expressando o que pensam a respeito, através da construção de um diálogo. Há uma corrente majoritária na pedagogia moderna que diz que a educação deve sempre estar permeada pela dialogicidade encontrada em Freire, nas suas relações de aprendizagem aluno-professor. Contudo, há uma ênfase no legado freiriano da importância da dialogicidade como instrumento da dialética que conduz a mudança transformadora: "Minha perspectiva é dialética e fenomenológica. Eu acredito que daqui temos um olhar para vencermos esse relacionamento oposto entre teoria e práxis: superando o que não deve ser feito num nível idealista" (FREIRE apud TORRES, 1998, p. 82).

Empoderar sujeitos que vivenciam o papel de aprendizes não é sobrepor uma ideologia sobre as demais por força de um discurso, mas possibilitar a vazão aos vários discursos existentes e vivenciar sua própria sucumbência perante o pensamento crítico e liberto dos educandos, então capazes de discernir o que é verdade e o que é engodo. É em plenitude acreditar no ser humano, na sua libertação e na força do diálogo. Nesse sentido, em "Pedagogia do Oprimido", Freire diz que "a conquista implícita do diálogo é a do mundo pelos sujeitos dialógicos, não a de um pelo outro, conquista do mundo pela libertação dos homens. Não há diálogo, porém, se não há um profundo amor ao mundo e aos homens" (FREIRE, 1987, p. 79).

\section{UTOPIA X REALIDADE: UM OLHAR SOBRE A PRÁXIS FREIRIANA}

A práxis freiriana é aproximação da teoria humanista com a prática transformadora. Uma das principais preocupações de Freire era que suas palavras não se tornassem utopia, que seu discurso não fosse idealista. Freire (1997), em "Pedagogia da Autonomia", evidencia essa natureza humanista, sempre em construção, sempre trazendo seus ideais para o campo prático: “Gosto de ser gente porque, inacabado, sei que sou um ser condicionado, mas consciente do inacabamento, sei que posso ir mais além dele. Esta é a diferença profunda entre o ser determinado e o ser conciliador e o ser condicionado" (FREIRE, 1997, p. 59). Em uma de suas mais emblemáticas obras, “Pedagogia do Oprimido", Freire retoma a importância de avançar a teoria para o campo 
prático: "Não há denúncia verdadeira sem compromisso de transformação, nem este sem ação" (FREIRE, 1987, p.78).

Nessa mesma obra, Freire traz o sentido de coletividade, afinidade, à medida que, enquanto seres oprimidos, padecem das mesmas mazelas sociais e encontram forças entre si através do processo de conscientização: "Aos esfarrapados do mundo e aos que nele se descobrem e, assim descobrindo-se, com eles sofrem, mas, sobretudo, com eles lutam" (1993, p.23).

Nesse aspecto, Freire sempre procurou tratar os temas sob um viés mais universal, abstraindo-os de quaisquer convicções partidárias ou inclinações pessoais. Pensou no ser humano de modo holístico, pensou amar ao próximo em primeiro lugar, e sugeriu para resolução dos problemas a utilização do diálogo como a principal ferramenta. Esse sentimento de humanidade fica evidenciado em sua postura contrária à antropologia tradicional, que ele sugere ser simplista e que acentua o individualismo:

\begin{abstract}
Visão antropológica tradicional sugere uma dicotomia inexistente homensmundo. Homens simplesmente no mundo e não com o mundo e com os outros. Homens espectadores e não recriadores do mundo. Concebe a sua consciência como algo especializado neles e não aos homens como "corpos conscientes". (Freire, 1993, p. 63).
\end{abstract}

Corroborando com essa ideia, Zitkoski diz que "A educação para Freire deve ser trabalhada intencionalmente para humanizar o mundo por meio de uma formação cultural e da práxis transformadora de todos os cidadãos, autênticos sujeitos de sua história, construída pela participação coletiva e democrática" (ZITKOSKI, 2010, p. 24).

A esse caráter dialético, ou seja, "dialética como fazedora de realidade e não como reflexo" (Freire, 1994), entre outros fatores, atribui-se a atemporalidade da sua obra e a aceitação e repercussão do seu legado no meio internacional, inclusive em países considerados de primeiro mundo.

Muitos atribuem a ele a invenção do método revolucionário para alfabetização de jovens e adultos, tendo como caso mais famoso a experiência na cidade de Angicos, no Rio Grande do Norte. Porém, ele sempre ressaltava que não criou nenhum método ou fórmula do conhecimento, que suas atitudes e decisões estavam apenas pautadas em princípios universais e atemporais, e quem os cultivasse seria capaz de bons feitos em qualquer época e em qualquer circunstância. Alguns princípios encontrados imbuídos na obra freiriana são: amor, afetividade, respeito, dignidade, ética, solidariedade, entre outros. 
Desse modo, as relações interpessoais entre educadores e educandos no contexto pedagógico devem ser pautadas por tais princípios, assim como pelo respeito mútuo e pela construção do conhecimento, de forma colaborativa, em via de mão dupla, através de uma liderança democrática por parte de educadores. Estes, ao se solidarizarem com os educandos enquanto seres aprendentes e humanos, libertam também a si próprios, libertando seus educandos da ignorância e das amarras do pensamento.

\section{CONSIDERAÇÕES FINAIS}

A educação nacional está em crise, sendo causa e efeito de um fenômeno sistêmico. Falta estrutura adequada na rede pública. Falta, em toda rede nacional de ensino, valorização e reconhecimento dos profissionais de educação. Faltam, de maneira geral, investimentos na educação e em outras áreas pelos governantes. Falta uma ideologia a ser perseguida nos ambientes formais de educação. Falta também a consciência em toda sociedade de que o ato de educar não começa e nem termina no ambiente escolar, acadêmico ou similar; pois educar não é mera transmissão de conhecimento, mas acontece a todo o momento e em todos os ambientes. Falta uma educação que prepare para a vida em sociedade, baseada em noções de cidadania, de respeito ao próximo e às diferenças, que desenvolva potencialidades e capacidades do ser humano, que trabalhe o aspecto social e político inerente a todos os indivíduos. Fica a certeza de que faltam muitas outras coisas na educação brasileira, ainda que não caibam no escopo deste trabalho.

Com o intuito de preencher essas e outras lacunas encontradas na educação, foi realizada uma análise das relações interpessoais sobre aspectos pedagógicos entre educador e educando. Constatou-se, como um caminho para superar a crise na educação, a formação de uma educação fundamentada na práxis freiriana. Ou seja, o indivíduo, a partir do momento que toma consciência de sua realidade e entende o que a sustenta, torna-se capaz de transformar a sua realidade e a da coletividade circundante.

Desse modo, Paulo Freire aponta a educação problematizadora como o meio para que venha a se concretizar o verdadeiro aprendizado, aquele que agrega valor e o torna mais eficaz. Não restringe a educação como mera replicação de conceitos ou a exposição de conteúdos vagos e pontuais, sem fazer as devidas e pertinentes ligações entre si. Para Paulo Freire o conhecimento é sistêmico, é uma rede, onde cada pessoa apreende algo 
sempre relacionando com a sua visão de mundo. No seu legado, há sempre a constatação que o indivíduo se educa socialmente e não sozinho ou através unicamente do professor, corroborando com a ideia de que educar é algo muito maior do que simplesmente assimilar informações. É vivenciar aquele conhecimento recebido, e é também construir uma sociedade mais ética, moral e socialmente mais justa, por meio das interações e relações construídas socialmente.

Para a melhor compreensão do enfoque dado neste trabalho, alguns conceitos como liderança e empoderamento foram retomados sob um olhar pedagógico. Dessa forma, constatou-se a liderança do indivíduo no papel de educador se dá pela consciência do seu papel e da capacidade de conscientizar e influenciar positivamente no desenvolvimento intelectual do educando, por meio da estimulação do raciocínio crítico e problematizador.

Por outro lado, o empoderamento por parte do educando acontece quando ele, já consciente da realidade e das causas por trás dela, torna-se um agente transformador, empoderado pelo sentimento de mudança e de luta por condições mais igualitárias para todos. Nesse sentido, Gadotti (1995) nos alerta que ser professor exige um componente ético essencial: compromisso com a emancipação das pessoas.

Pudemos definir neste artigo o termo empoderamento como a representação da busca por maior autonomia por parte do educando através do conhecimento. Neste sentido, Paulo Freire ainda alerta que educar é um ato político e frequentemente permeado por relações de poder, havendo opressores e oprimidos.

Por fim, o pensamento freiriano não se limita ao contexto pedagógico. Abordar um assunto sob a luz dos ideais de Freire é falar de princípios filosóficos universais e, antes de tudo, humanos, como amor, afetuosidade, honestidade, dignidade, cidadania, ética e tantos outros. Desse modo, pensar na educação sob a ótica freiriana é essencialmente acreditar no ser humano e na construção de um mundo melhor, através do amor a si e a todos, contribuindo assim para a construção de uma sociedade menos autodestrutiva e egoísta.

\section{REFERÊNCIAS}

CHIAVENATO, Idalberto. Administração: teoria, processo e prática. $3^{a}$ edição. São Paulo: Pearson education do Brasil, 2000.
COVEY, S. Liderança baseada em princípios. São Paulo: Cutrix, 1998. 
DESSEN, M. C.; PAZ, M. G. T. Bem-estar pessoal nas organizações: o impacto de configurações de poder e características de personalidade. Psic.: Teor. e Pesq., Brasília, v. 26, n. 3, p. 549-556, jul/set, 2010.

FIORI, E. M. Aprender a dizer a sua palavra. In: Freire, P. Pedagogia do Oprimido. 22. ed. Rio de Janeiro: Paz e Terra, 1993.

FREIRE, Paulo. Educação como prática da liberdade. Série Ecumenismo e Humanismo, v. 5. Rio de Janeiro: Paz e Terra, 1969.

FREIRE, Paulo. Pedagogia da autonomia. São Paulo: Paz e Terra, 1997.

FREIRE, Paulo. Pedagogia da esperança. São Paulo: Paz e Terra, 1994.

FREIRE, Paulo. Pedagogia do oprimido. 17. ed. Rio de Janeiro: Paz e Terra, 1987.

FREIRE, Paulo; SHOR, Ira. Medo e Ousadia: o cotidiano do professor. 3. ed. Rio de Janeiro: Paz e Terra, 1986.
GADOTTI, M. et. Al. (org). Paulo Freire: uma biobibliografia. São Paulo: Cortez, UNESCO e Fundação Paulo Freire, 1995.

GARDNER, H. Mentes que lideram: uma anatomia da liderança. Porto Alegre: Artes Médicas, 1996.

JACOBS, T. O. Leadership and exchange in formal organizations. Alexandria, VA: Human Research Organization, 1970.

WILSON, Sybil E. A educação abre as portas para um mundo melhor. Educação. Porto Alegre, v. 34, n. 2, p. 241-251, mai./ago. 2011.

ZITKOSKI, Jaime José. Paulo Freire \& a Educação. 2. ed. Belo Horizonte: Autêntica Editora, 2010. 